\title{
NEW PHA PRODUCTS USING UNRELATED CARBON SOURCES
}

\author{
Fernanda Matias ${ }^{1,2}$, Maria Filomena de Andrade Rodrigues ${ }^{2 *}$ \\ ${ }^{1}$ Universidade de São Paulo, Instituto de Ciências Biomédicas, São Paulo, SP, Brasil; ${ }^{2}$ Instituto de Pesquisas Tecnológicas do \\ Estado de São Paulo, Laboratório de Biotecnologia Industrial, São Paulo, SP, Brasil.
}

Submitted: February 23, 2010; Approved: June 06, 2011.

\begin{abstract}
Polyhydroxyalkanoates (PHA) are natural polyesters stored by a wide range of bacteria as carbon source reserve. Due to its chemical characteristics and biodegradability PHA can be used in chemical, medical and pharmaceutical industry for many human purposes. Over the past years, few Burkholderia species have become known for production of PHA. Aside from that, these bacteria seem to be interesting for discovering new PHA compositions which is important to different industrial applications. In this paper, we introduce two new strains which belong either to Burkholderia cepacia complex (Bcc) or genomovar-type, Burkholderia cepacia SA3J and Burkholderia contaminans I29B, both PHA producers from unrelated carbon sources. The classification was based on 16S rDNA and recA partial sequence genes and cell wall fatty acids composition. These two strains were capable to produce different types of PHA monomers or precursors. Unrelated carbon sources were used for growth and PHA accumulation. The amount of carbon source evaluated, or mixtures of them, was increased with every new experiment until it reaches eighteen carbon sources. As first bioprospection experiments staining methods were used with colony fluorescent dye Nile Red and the cell fluorescent dye Nile Blue A. Gas chromatography analysis coupled to mass spectrometry was used to evaluate the PHA composition on each strain cultivated on different carbon sources. The synthesized polymers were composed by short chain length-PHA (scl-PHA), especially polyhydroxybutyrate, and medium chain length-PHA (mcl-PHA) depending on the carbon source used.
\end{abstract}

Key words: Burkholderia; Burkholderia cepacia complex; Genomovar-type; mcl-PHA; polyhydroxyalkanoates; polyhydroxybutyrate.

\section{INTRODUCTION}

Polyhydroxyalkanoates (PHA) are biological polymers produced by a large selection of bacteria as intracellular inclusions usually accumulated when in starvation of phosphate or nitrogen source and excess of carbon source (3,
18). PHA compounds are biodegradable when compared to synthetic plastics and are produced from renewable resources (20). These polymers can be grouped in two major classes according to the length of the side chain: short chain lengthpoly[hydroxyalkanoate] (scl-PHA), with monomers from three to five carbons, and medium chain length-poly

*Corresponding Author. Mailing address: Research developed at: Instituto de Pesquisas Tecnológicas do Estado de São Paulo, Laboratório de Biotecnologia Industrial. Rua Professor Almeida Prado, 532. São Paulo, São Paulo, Brazil, 05508-901.; Tel.: +55 11 37674315 Fax: +55 11 37195729 .; E-mail: filomena@ipt.br 
[hydroxyalkanoate] (mcl-PHA), with monomers containing more than five carbons in the chain $(20,31)$. In the scl-PHA class are the most known polymers in terms of prokaryotic metabolism and physic-chemical properties, the P3HB (poly-3hydroxybutyrate) and its co-polymer P3HB-co-P3HV, poly[3hydroxybutyrate-co-3-hydroxyvalerate] $(3,24)$. The first report about PHA was in 1920s when Lemoigne unintentionally stained a Bacillus megaterium strain, observed intracellular granules and defined its chemical characteristics (16). In the 1970s, the search for new PHA-producers bacteria increased due to the first petroleum global crisis and bacteria belonging to Pseudomonas, Azotobacter, Rhizobium, Nocardia and other genera started to be studied, generating the greatest majority of articles on 1980s and 1990s $(3,20,35)$. The first industrial production started to become a reality by the use of Cupriavidus necator, formerly classified as Ralstonia eutropha or Alcaligenes eutrophus (37), in the 1980s. This bacterium became the molecular and cellular model for PHA production and for industrial applications $(3,19,20)$. Since the 1990's, a bacteria belonging to Burkholderia genus started to be studied for PHA production (26). This genus proved to be interesting for future industrial application due to its capacity to produce different types of PHA such as P3HB, poly-3hydroxypentenoate (P3HPE), poly-3-hydroxyoctanoate (P3HO) and poly-3-hydroxydecanoate (P3HD) $(12,27,36)$. In this paper we introduce two Genomovar-type Burkholderia as producers of different PHA from unrelated carbon sources.

\section{MATERIALS AND METHODS}

\section{Bacterial strain and growth conditions}

The soil isolated strains I29B and SA3J (22) were maintained on solid ISP9 medium $(29,22)$ supplemented with $10 \mathrm{~g} / 1$ glucose or $10 \mathrm{~g} / 1$ glucose with $1 \mathrm{~g} / 1$ casein as carbon sources. The cultures were incubated at $30{ }^{\circ} \mathrm{C}$ during $24-72 \mathrm{~h}$. For cell wall fatty acids composition, strains were cultivated on Trypticase Soy Broth Agar, which consists of 30 g/l Trypticase Soy Broth (Oxoid) and $15 \mathrm{~g} / \mathrm{l}$ of agar, during $24 \mathrm{~h}$ at $28{ }^{\circ} \mathrm{C}$. To produce PHA, strains I29B and SA3J were cultivated on nine different carbon sources (starch, carboxymethylcellulose, cellulose, fructose, glycerol, glucose, lactose, pectin, sucrose) and nine different combinations of carbon sources (starch plus casein, cellulose plus casein or sucrose, glycerol plus casein, glucose plus casein, lactose plus casein, pectin plus cellulose or sodium citrate, sucrose plus casein) on mineral medium ISP9 until reach $20 \mathrm{~g} / 1$ of total carbon source. When two carbon sources were added, $10 \mathrm{~g} / \mathrm{l}$ of each one were used.

\section{Identification of strains}

The DNA extraction was performed as described by Ausubel and colleagues (4). The 16S rDNA was amplified with universal primers 27F and 1492R (16) using 2X PCR Master Mix (Fermentas) according to the manufacturer's instructions. In order to complement the identification, BCR1 and BCR2 primers (21) were used to amplify the recA gene. Sequences were obtained on MegaBACE 1000 sequencer using manufacture's protocols (GE Health care). Sequences obtained from strains were deposited in GenBank (GenBank accession number shown): GQ397110, GQ397111, GQ397112, GQ397113.

\section{Bioinformatics}

Sequence assembly was performed using Bioedit 7.0.9.0 (11) software package. Phylogenetic and molecular evolutionary analyses were conducted using MEGA version 4 (33) software package. Sequences were aligned with each other and compared to sequences deposited in DNA databases, using software such as search in Ribosomal Database Project - RDP (6) and Basic Local Alignment and Search Tool - Blast (2). Classification using bacterial 16S rDNA gene was based on Bayesian test with $80 \%$ confidence available online at RDP classifier software (39).

\section{Cell wall fatty acids composition}

Cell wall fatty acids composition analysis was conducted as indicated by software manufacturer instructions (23). 
Briefly, samples were saponified ( $1 \mathrm{ml}$ of a mixture of $45 \mathrm{~g}$ sodium hydroxide, $150 \mathrm{ml}$ methanol and $150 \mathrm{ml}$ distilled water), methylated ( $2 \mathrm{ml}$ of a mixture of $325 \mathrm{ml}$ certified $6.0 \mathrm{~N}$ hydrochloric acid and $275 \mathrm{ml}$ methyl alcohol) followed by an extraction with $1.25 \mathrm{ml}$ of mixture of $200 \mathrm{ml}$ hexane and 200 $\mathrm{ml}$ methyl tert-butyl ether and a cleanup using $3 \mathrm{ml}$ of a mixture of $10.8 \mathrm{~g}$ sodium hydroxide dissolved in $900 \mathrm{ml}$ distilled water. After that, samples were injected on Agilent 6580 gas chromatography (GC) containing 7683 automatic injector and Ultra 2 capillary using Hydrogen gas as mobile phase, Nitrogen gas as make-up and FID as detector. An external calibration standard based on a mixture of the straight chained saturated fatty acids from 9 to 20 carbons in length (9:0 to 20:0) and five hydroxy acids (7).

\section{PHA production and analysis}

Strains were grown on solid medium, starvation of nitrogen $\left(0.264 \mathrm{~g} / 1\left(\mathrm{NH}_{4}\right)_{2} \mathrm{SO}_{4}\right)$ and in the presence of Nile Red (30) with different carbon sources. A sample of each strain from similar plates containing the different carbon sources were fixed on microscopy glass and colored with a fluorescent solution of Nile Blue A (10). Subsequently, strains were cultivated in $50 \mathrm{ml}$ of liquid ISP9 medium combined with different carbon sources and no nitrogen starvation for 7 to 14 days. Cultures were harvested by centrifugation, frozen at -20 ${ }^{\circ} \mathrm{C}$ and lyophilized. From 18 to $20 \mathrm{mg}$ of lyophilized product were submitted to propanolysis (25) and samples were analyzed by gas chromatography (GC) (5890A Hewlet Packard with HP-5 Agilent column) with or without mass spectrometer (GC-MS) (GCMS-QP5050A Shimadzu with HP-5 Agilent column) and calibrations curves based on scl and mcl PHA as described previously by Gomez et al. (9) and Matias et al. (23).

\section{RESULTS}

\section{Identification of strains}

A fragment nearby $1.5 \mathrm{~Kb}$ belonging to $16 \mathrm{~S}$ rDNA was obtained. To complete the identification of I29B and SA3J strains, the BCR1/BCR2 primers pair were used for $r e c A$ gene amplification and an approximately $1 \mathrm{~KB}$ fragment of each strain was obtained. All the sequences acquired were treated on Bioedit and compared to sequences deposited in DNA databases, using software such as search in RDP and Blast. In both cases, the most similarity was obtained when compared to Burkholderia cepacia complex (Bcc) strains (96\%). Analyzing the $16 \mathrm{~S}$ rDNA plylogenetic tree, two major groups are shown (Figure 1). The first group showed the inclusion of Burkholderia sp. I29B. It should be noted that all representatives are genomovar-type bacteria and showed $15 \%$ of similarity with that cluster and there is more similarity to clusters containing B. cepacia, B. lata and B. mana. Moreover, Burkholderia sp. SA3J strain showed the most dissimilar $16 \mathrm{~S}$ rDNA sequence providing the second group on phylogenetic tree. The recA gene analysis was not enough to classify both strains. The phylogenetic tree analysis showed more similarity to B. cepacia and B. contaminans strains (Figure 2). Therefore, to distinguish the strains, cell wall fatty acids compositions were analyzed. Strain I29B presented a large amount of lipids containing hydroxides and prevalent lipids formed in a 15 carbon chain $(\mathrm{C} 15), 16$ carbon chain $(\mathrm{C} 16)$ and 18 carbon chain (C18). The library database software generated a similarity of $59.6 \%$ to B. cepacia subgroup B and $43.6 \%$ similarity to Burkholderia andropogonis. The SA3J strain showed $94.6 \%$ similarity to B. cepacia subgroup B and $75.7 \%$ similarity to $B$. cepacia subgroup A. The predominant lipids identified in this strain were $\mathrm{C} 18$ and $\mathrm{C} 16$ and a variety of hydroxides.

\section{PHA production}

Eighteen carbon sources were evaluated for reporting the growth and polymer accumulation by I29B and SA3J strains. First both strains were cultivated on solid media and PHA production was analyzed by two different staining methods (Table 1). The two methods were used in order to reduce the 
sampling error. It is possible to check differences obtained in these two staining. Comparing Nile Red to Nile Blue it was observed that Nile Blue was more responsive to PHA accumulation than Nile Red. Strain I29B had not shown fluorescence when cultivated on starch, glycerol with casein, sucrose with cellulose and sucrose with casein using Nile Red. When it was re-cultured on these media and stained with Nile Blue, these strain showed positive results. Based on these two experiments, it was verified PHA composition produced on each of carbon source, using GC analysis. There is variability on PHA composition according to carbon source used (Table 2). 3-hydoxybutyrate (3HB) was the most usual monomer produced by strains from different carbon sources and 3-hydroxyheptanoate (3HHp) was the second more abundant monomer (Figure 3).

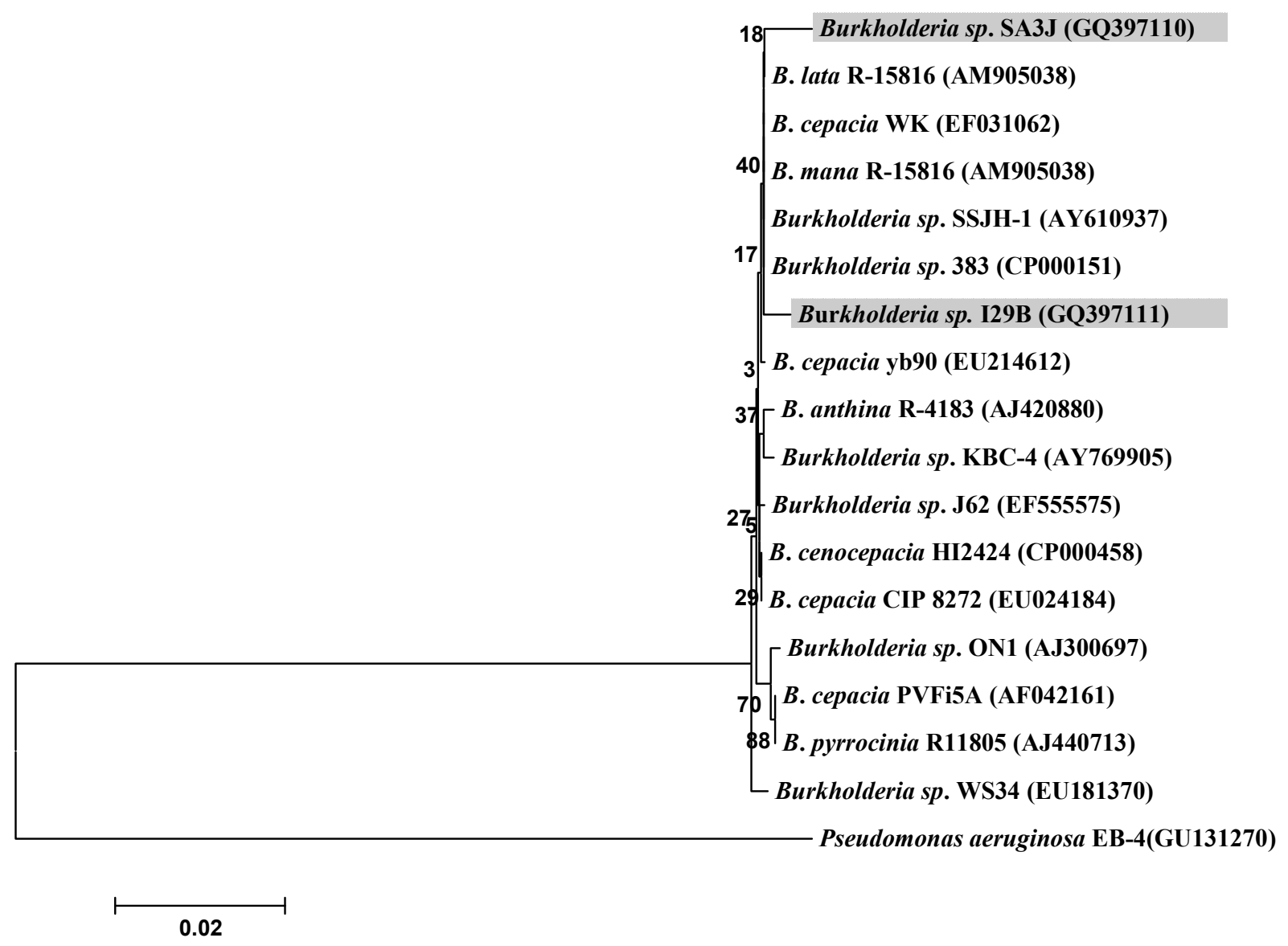

Figure 1. Partial 16S rDNA gene phylogenetic tree construction of Burkholderia sp. I29B and Burkholderia sp. SA3J based on Neighbor-Joining with bootstrap (500x) and Tamura 3-parameters phylogenetic test (40). Pseudomonas aeruginosa 16S rDNA partial sequence gene used as outgroup species. 


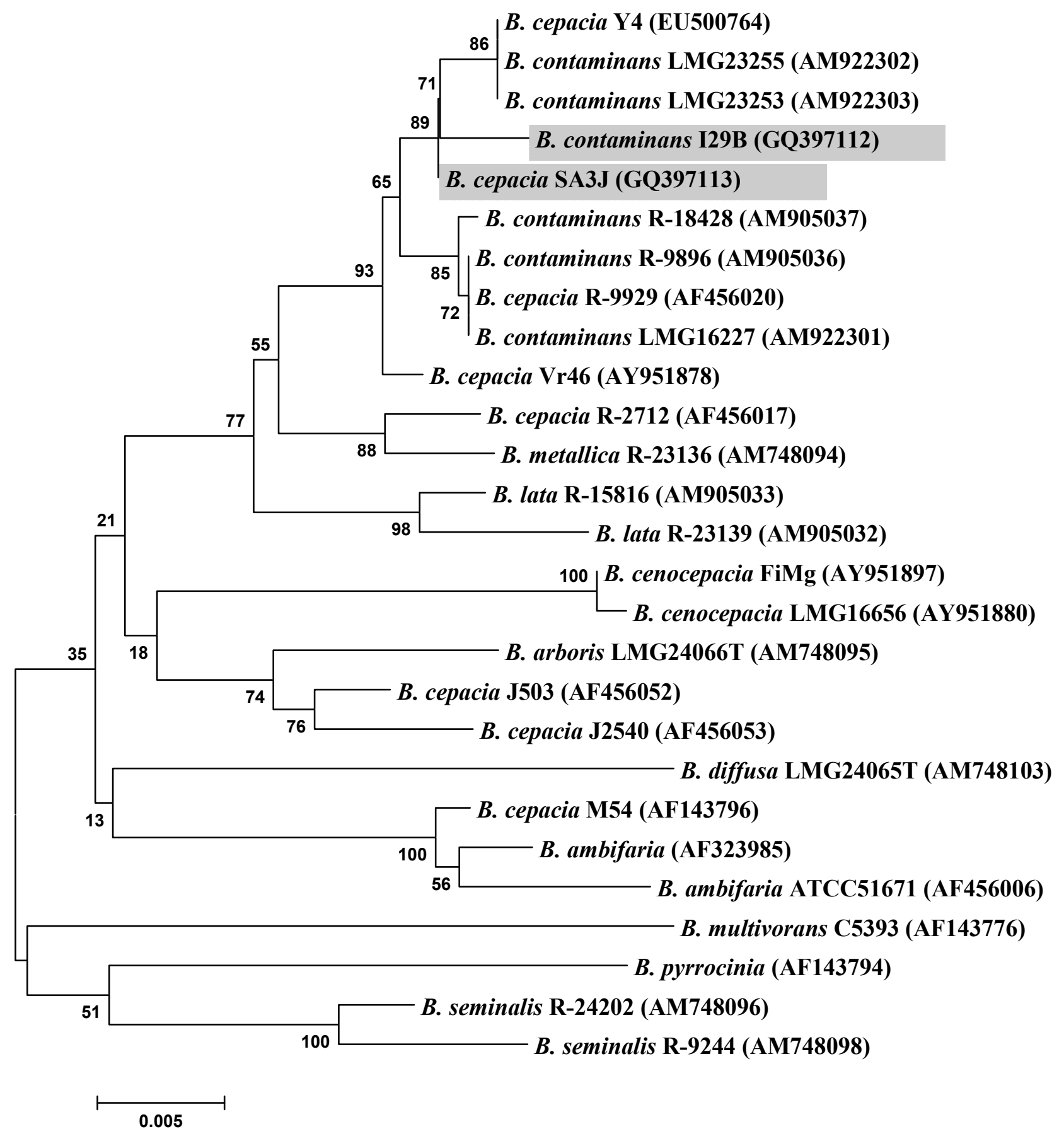

Figure 2. Partial recA gene phylogenetic tree construction of Burkholderia sp. I29B and Burkholderia sp. SA3J based on Neighbor-Joining with bootstrap (500x) and Tamura 3-parameters phylogenetic test (40). 


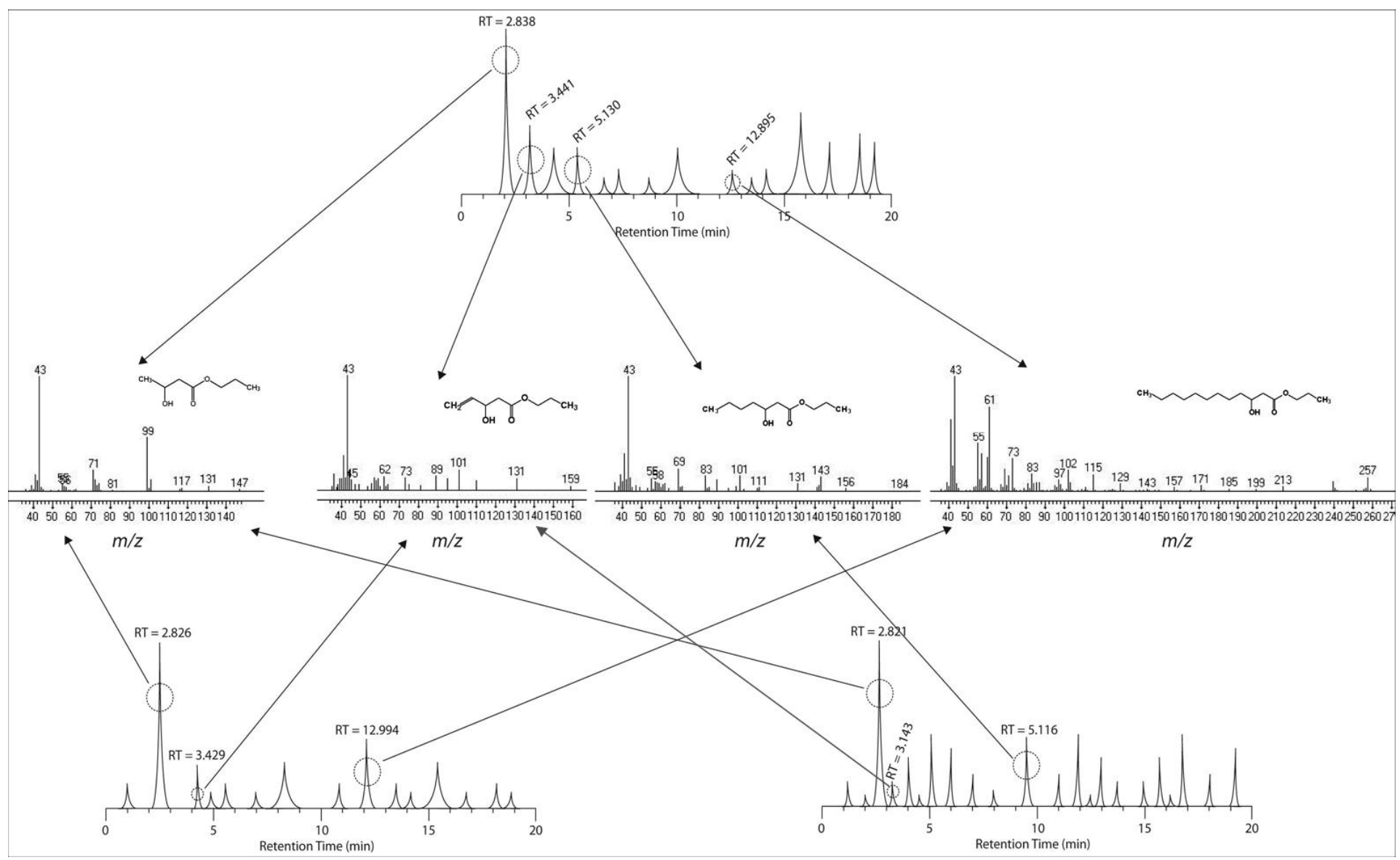

Figure 3. GC-MS analysis of PHA accumulation when B. contaminans I29B and B. cepacia SA3J were cultivated using different carbon sources. Upper GC: Propyl esters of PHA when B. contaminans I29B was cultivated using glycerol (20g/l) and casein $(2 \mathrm{~g} / \mathrm{l})$ as carbon source; $3 \mathrm{HB}, \mathrm{RT}=2.838 ; 3 \mathrm{HPE}=3.441 ; 3 \mathrm{HHp}=5.130 ; 3 \mathrm{HDd}=12.895$. Downstream left: Propyl esters of PHA when $B$. cepacia SA3J was cultivated using pectin $(20 \mathrm{~g} / \mathrm{l})$ as carbon source; $3 \mathrm{HB}$, RT $=2.826$; $3 \mathrm{HPE}=3.429 ; 3 \mathrm{HDd}=12.994$. Downstream right: Propyl esters of PHA when B. contaminans I29B was cultivated using cellulose (20g/l) and casein (2g/l) as carbon source; $3 \mathrm{HB}, \mathrm{RT}=2.821 ; 3 \mathrm{HPE}=3.143 ; 3 \mathrm{HHp}=5.116$.

Table 1. Growth and accumulation of PHA on different carbon sources using staining with Nile Red and Nile Blue.

\begin{tabular}{|c|c|c|c|c|c|c|c|c|c|c|c|c|c|c|c|}
\hline \multirow{2}{*}{ Strain } & \multirow[t]{2}{*}{ Dye } & \multicolumn{14}{|c|}{ Carbon source utilization and fluorescence using stains } \\
\hline & & 1 & 2 & 3 & 4 & 5 & 6 & 7 & 8 & 9 & 10 & 11 & 12 & 13 & 14 \\
\hline & Nile Red & + & + & - & NT & + & NT & - & + & NT & + & - & NT & - & + \\
\hline I29B & Nile Blue & + & + & + & + & + & + & + & + & + & + & + & + & + & + \\
\hline & Nile Red & - & + & + & NT & + & NT & - & + & NT & + & - & NT & + & + \\
\hline SA3J & Nile Blue & + & + & + & + & + & + & \pm & + & + & + & + & + & + & + \\
\hline
\end{tabular}

$(-)$ - good growth and no fluorescence; $(+)$ - growth and fluorescence; $( \pm)$ - little growth with good fluorescence; NT - Not tested. 1- glycerol, 2- pectin, 3- starch, 4- cellulose, 5- lactose, 6- sucrose, 7- glycerol and casein, 8- starch and casein, 9cellulose and casein, 10- lactose and casein, 11- sucrose and casein, 12- pectin and cellulose, 13- sucrose and cellulose, 14- pectin and sodium citrate. 
Table 2. PHA composition of B. contaminans I29B and B. cepacia SA3J after cultivation on different carbon sources.

\begin{tabular}{|c|c|c|c|c|c|c|c|c|}
\hline \multirow[b]{2}{*}{ Strain } & \multirow[b]{2}{*}{ Carbon source } & \multicolumn{7}{|c|}{ 3-hydroxypropyl esters (mol\%) } \\
\hline & & 3HB & 3HPE & 3ННр & $3 \mathrm{HO}$ & $3 \mathrm{HN}$ & 3HD & 3HDd \\
\hline \multirow[t]{18}{*}{ I29B } & Glucose & 99.45 & - & 0.41 & - & 0.14 & - & - \\
\hline & Glucose casein & 100 & - & - & - & - & - & - \\
\hline & Sucrose & 92.99 & 0.08 & 6.75 & - & 1,49 & - & - \\
\hline & Sucrose casein & 8.49 & 2.91 & - & 0.94 & - & 31.16 & 56.50 \\
\hline & Starch & 33.32 & 1.10 & 59.88 & - & 5.70 & - & - \\
\hline & Starch casein & 34.00 & - & 61.05 & - & 4.95 & - & - \\
\hline & Lactose & 83.22 & 2.27 & 14.51 & - & - & - & - \\
\hline & Lactose casein & 96.48 & - & 1.14 & - & - & - & 2.38 \\
\hline & Fructose & 92.61 & - & 7.39 & - & - & - & - \\
\hline & Pectin & 33.06 & - & - & - & - & - & 66.94 \\
\hline & Pectin sodium citrate & - & 15.72 & 12.79 & - & 30.96 & - & 40.53 \\
\hline & Pectin cellulose & - & 5.72 & 63.08 & - & 13.87 & - & 17.33 \\
\hline & Glycerol & 100 & - & - & - & - & - & - \\
\hline & Glycerol casein & 52.44 & 26,53 & 17.00 & - & - & - & 4.03 \\
\hline & Cellulose & 100 & - & - & - & - & - & - \\
\hline & Cellulose casein & 66.93 & 6.65 & 26.42 & - & - & - & - \\
\hline & Cellulose sucrose & 95.57 & - & 4.43 & - & - & - & - \\
\hline & Carboxymethylcellulose & 100 & - & - & - & - & - & - \\
\hline \multirow[t]{18}{*}{ SA3J } & Glucose & 12.00 & 0.01 & 0.02 & - & 0.06 & - & 87.91 \\
\hline & Glucose casein & 100 & - & - & - & - & - & - \\
\hline & Sucrose & 98.41 & - & 1,51 & - & 0,08 & - & - \\
\hline & Sucrose casein & 91.84 & 2.91 & 2.61 & 2.64 & - & - & - \\
\hline & Starch & 29.90 & 1.54 & 64.70 & - & 3.86 & - & - \\
\hline & Starch casein & 38.53 & 0.80 & 60.67 & - & - & - & - \\
\hline & Lactose & 89.80 & 1.80 & 8.40 & - & - & - & - \\
\hline & Lactose caseína & 98.98 & - & 1.02 & - & - & - & - \\
\hline & Fructose & 87.26 & - & 12.40 & - & 0.34 & - & - \\
\hline & Pectin & 59.55 & 14.67 & - & - & - & - & 25.78 \\
\hline & Pectin sodium citrate & - & 21.59 & - & - & - & - & 78.41 \\
\hline & Pectin cellulose & - & 5.14 & 53.36 & - & 15.20 & - & 26.30 \\
\hline & Glycerol & 99.15 & 0.46 & 0.39 & - & - & - & - \\
\hline & Glycerol casein & 96.67 & - & 3.33 & - & - & - & - \\
\hline & Cellulose & 100 & - & - & - & - & - & - \\
\hline & Cellulose casein & - & 14.57 & 85.43 & - & - & - & - \\
\hline & Cellulose sucrose & 93.47 & 0.53 & 6.00 & - & - & - & - \\
\hline & Carboxymethylcellulose & 100 & - & - & - & - & - & - \\
\hline
\end{tabular}

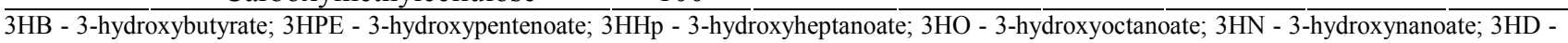
3-hydroxydecanoate; 3HDd - 3-hydroxydodecanoate.

\section{DISCUSSION}

The Burkholderia genus is known for high similarity of 16S rDNA gene between species, especially to those belonging to Burkholderia cepacia complex (Bcc) or genomovar-type (38). The Bcc bacteria are well studied as opportunistic pathogens of humans, with or without cystic fibrosis, and as plants endophytics $(5,8,13)$. Most of $16 \mathrm{~S}$ rDNA gene sequences belonging to some representatives of genomovartype bacteria are not available on DNA databases which could difficult the finding of similarities between neighborhoods (Figure 1). For this reason, to complete identification of strains the 16S rDNA gene analysis was not enough, but it has provided the genus and evidences that these strains could 
belong to genomovar-type Burkholderia group. Nowadays, trying to solve the species identification problem in Bcc, rec $\mathrm{A}$ gene has been used with success. In order to distinguish species of the strains used in this work, BCR1 and BCR2 primers were used. Alignment of sequences showed that both strains aligned very well with the recently discovered $B$. contaminans, which is quite evident in the Neighbor-Joining phylogenetic tree (Figure 2). But similarities between B. cepacia and $B$. contaminans were very extensive. Thereupon, another experiment was necessary to distinguish species. When the composition and concentrations of cell wall fatty acids of each strain, using a calibration standard curve made of a mixture of fatty acids $(7,23)$, was compared to MIS software library, it was possible to observe that I29B strain showed low similarity to $B$. cepacia while SA3J strain showed high similarity. Crossing experiments results it was possible to finally classify strains as: Burkholderia cepacia SA3J strain and Burkholderia contaminans I29B strain.

Both strains were capable to produce P3HB using different types of carbon source. B. contaminans I29B showed high capacity to accumulate $\mathrm{P} 3 \mathrm{HB}$ using most of carbon sources used. An interesting fact is that when both strains were cultivated on pectin or pectin combined with other carbon sources they accumulated mcl-PHA and P3HB. Production of mcl-PHA is well studied on Pseudomonas group (3, 20, 40). In this genus, the production is frequently obtained when the carbon source is related to mcl-PHA desired and even then, natural production of poly-3-hydroxydodecanoate (P3HDd) is obtained as a secondary PHA reaching low amounts in the total polymer percentage content $(15,28)$. The Burkholderia genus has been showing good perspective for scl and mcl-PHA production, such as $\mathrm{P} 3 \mathrm{HB}, \mathrm{P} 3 \mathrm{HV}$, P3HPE, poly-3hydroxyhexanoate (P3HHx), P3HO and P3HD (1, 12, 14, 26). When cultivated on glucose, B. caryophylli was capable to accumulate P3HD as major PHA, accumulating P3HB blended with P3HD when cultivated on butyrate (12). Rodrigues et al. (26) isolated a strain of Burkholderia cepacia IPT64 from sugar cane plantations, that was able to produce an unusual polymer composed of $\mathrm{P} 3 \mathrm{HB}$ and $\mathrm{P} 3 \mathrm{HPE}$ using sucrose as sole carbon source (36). In this study, Burkholderia cepacia SA3J and Burkholderia contaminans I29B were capable to produce different types of PHA monomers using unrelated carbon sources to growth, such as sucrose and sucrose with casein, producing 3HB, 3HPE, 3HHp, 3HO (3-hydroxyoctanoate), $3 \mathrm{HN}, 3 \mathrm{HD}$ and $3 \mathrm{HDd}$.

One unexpected data was given by the presence of $3 \mathrm{HHp}$ that was confirmed using CG-MS. The presence of 3HPE, however, has been reported in other Bcc bacterium, B. cepacia IPT64, DSMZ 9242 (26) and, apparently, it is not a rare event in bacteria belonging to this group. Monomers of $3 \mathrm{HO}$ and $3 \mathrm{HD}$ were produced in some cases like B. contaminans I29B strain cultivated on sucrose with casein. B. contaminans I29B revealed more positive results in production and variability of PHA and assimilation of carbon source. Glucose, sucrose, sucrose with casein, fructose, pectin, pectin with sodium citrate and pectin with cellulose were preferable carbon sources and showed the most different compositions. B. cepacia SA3J had not accumulated as much PHA as B. contaminans I29B and preferred pectin, cellulose with sucrose, glucose and sucrose as carbon sources to produce different types of PHA.

It is important to remember that this is a preliminary study of bioprospection using different carbon sources for growth and to produce different types of PHA by these strains. Therefore, experiments were not performed aiming to achieve the best condition for PHA accumulation, but instead, to find out which PHA-types could be produced by these strains using unrelated carbon sources. This is the first report of the recently identified bacteria $B$. contaminans on producing PHA, especially mcl-PHA, which is a new finding for both strains.

\section{ACKNOWLEDGEMENTS}

We would like to thank Dr. Peter Vandamme, Dr. Itamar Soares de Melo and Márcia Maria Parma for their help in 
identifying strains, Adriano Vito for his help with the layout of this manuscript. Also FAPESP and CNPq for financial support.

\section{REFERENCES}

1. Alias, Z.; Tan, I.K.P. Isolation of palm oil-utilizing, polyhydroxyalkanoate (PHA)-producing bacteria by an enrichment technique. Bioresour. Technol. 96: 1229-1234, 2005.

2. Altschul, S.F.; Gish, W.; Miller, W.; Myers, E.W.; Lipman, D.J. Basic local alignment search tool. J. Mol. Biol. 215:403-410, 1990.

3. Anderson, A.A.; Dawes, E.A. Occurrence, metabolism, metabolic role, and industrial uses of bacterial polyhydroxyalkanoates. Microbiol. Rev. 54:450-472, 1990.

4. Ausubel, E.; Brent, R.; Kingston, R.E.; Moore, D.D.; Seidman, J.G.; Smith, J.A.; Stuhl, K. Short protocols in molecular biology. John Wiley, New York, 2002.

5. Carvalho, A.P.A.; Ventura, G.M.C.; Folescu, T.W.; D’Amoed, R.F.; Higa, L.; Teixeira, L.M.; Merquior, V.L.C.; Marques, E.A. Chronic infection of cystic fibrosis patient airways by a single clone of Burkholderia cepacia: replacement of non-mucoid to mucoid morphotype. Braz. J. Microbiol., 34:42-44, 2003.

6. Cole, J.R., Wang, Q.; Cardenas, E.; Fish, J.; Chai, B.; Farris, R.J.; Kulam-Syed-Mohideen, A.S.; McGarrell, D.M.; Marsh, T.; Garrity, G.M.; Tiedje, J.M. The Ribosomal Database Project: improved alignments and new tools for rRNA analysis. Nucleic Acids Res. 37 (Database issue):D141-D145, 2009.

7. Coenye, T.; Laevens, S.; Gillis, M.; Vandamme, P. Genotypic and chemotaxonomic evidence for the reclassification of Pseudomonas woodsii (Smith 1911) Stevens 1925 as Burkholderia andropogonis (Smith 1911) Gillis et al. 1995. Int J. Syst Evol Microbiol 51:183-185, 2001.

8. Dalmastri, C.; Baldwin, A.; Tabacchioni, S.; Bevivino, A.; Mahenthiralingam, E.; Chiarini, L.; Dowson, C. Investigating Burkholderia cepacia complex populations recovered from Italian maize rhizosphere by multilocus sequence typing. Environ. Microbiol. 9:1632$1639,2007$.

9. Gomez, J.G.C.; Rodrigues, M.F.A.; Alli, R.C.P.; Torres, B.B.; Bueno Netto, C.L.; Oliveira, M.S.; Silva, L.F. Evaluation of soil Gramnegative bacteria yielding polyhydroxyalkanoic acids from carbohydrates and propionic acid. Appl. Microbiol. Biotechnol. 45:785-791, 1996.

10. Greenspan, P.; Mayer, E.P.; Fowler, S.D. Nile red: a selective fluorescent stain for intracellular lipid droplets. J. Cell Biol. 100:965-973, 1985.

11. Hall, T.A. BioEdit: a user-friendly biological sequence alignment editor and analysis program for Windows 95/98/NT. Nucl. Acids Symp. Ser. 41:95-98, 1999.

12. Hang, X.; Zhang, G.; Wang, G.; Zhao, X.; Chen, G. PCR cloning of polyhydroxyalkanoate biosynthesis genes from Burkholderia caryophylli and their functional expression in recombinant Escherichia coli. FEMS Microbiol. Lett. 210:49-54, 2002.

13. Holmes, A.; Nolan, R.; Taylor, R.; Finley, R.; Riley, M.; Jiang, R.Z.; Steinbach, S.; Goldstein, R. An epidemic of Burkholderia cepacia transmitted between patients with and without cystic fibrosis. J. Infect. Dis. 179:1197-1205, 1999.

14. Keenan, T.M.; Nakas, J.P.; Tanenbaum, S.W. Polyhydroxyalkanoate copolymers from forest biomass. J. Ind. Microbiol. Biotechnol. 33:616$626,2006$.

15. Kroumova, A.B.; Wagner, G.J.; Davies, H.M. Biochemical observations on medium-chain-length polyhydroxyalkanoate biosynthesis and accumulation in Pseudomonas mendocina. Arch. Biochem. Biophys. 405:95-103, 2002.

16. Lane, D.J. 16S/23S rRNA sequencing. In: Stackebrandt, E., Goodfellow, M. (eds). Nucleic acid techniques in bacterial systematics. John Wiley and Sons, New York., USA, p. 115-175, 1991.

17. Lemoigne, M. Produits de déshydratation et de polymérisation de l'acide $\beta$-oxybutyrique. Bull. Soc. Chem. Biol. 8:770-782, 1926.

18. Lemoigne, M.; Roukhelman, N. Fermentation $\beta$-hydroxybutyrique. Caractérisation et évolution des produits de deshydration et de polymérisation de l'acide $\beta$-hydroxybutyrique. Ann. Ferment. 5:527-536, 1940.

19. Lenz, R.W.; Marchessault, R.H. Bacterial polyesters: biosynthesis, biodegradable plastics and biotechnology. Biomacromol. 6:1-8, 2005.

20. Madison, L.L.; Huisman, G.W. Metabolic engineering of poly(3hydroxyalkanoates): from DNA to plastic. Microbiol. Mol. Biol. Rev. 63:21-53, 1999 .

21. Mahenthiralingam, E.; Bischof, J.; Byrne, S.K.; Radomski, C.; Davies, J.E.; Av-Gay, Y.; Vandamme, P. DNA-based diagnostic approaches for identification of Burkholderia cepacia complex, Burkholderia vietnamiensis, Burkholderia multivorans, Burkholderia stabilis, Burkholderia cepacia genomovars I and III. J. Clin. Microbiol. 38:31653173,2000

22. Matias, F.; Bonatto, D.; Padilla, G.; Rodrigues, M.F.A.; Henriques, J.A.P. Polyhydroxyalkanoates production by actinobacteria isolated from soil. Can. J. Microbiol. 55:790-800, 2009.

23. MIS Operating Manual - Microbial identification system Sherlock. MIDI Inc., Newark, USA, 2001.

24. Reddy, C.S.K.; Ghai, R.; Rashmi; Kalia, V.C. Polyhydroxyalkanoates: an overview. Bioresour. Technol. 87:137-146, 2003.

25. Riis, V.; Mai, W. Gas chromatography determination of poly- $\beta$ hydroxybutyric acid in microbial biomass after hydrocloric acid propanolysis. J. Chromatogr. 445:285-289, 1998.

26. Rodrigues, M.F.A., Silva, L.F.; Gomez, J.G.C.; Valentin, H.E.; Steinbuchel, A. Biosynthesis of poly(3-hydroxybutyric acid-co-3hydroxy-4-pentenoic acid) from unrelated substrate by Burkholderia sp. 
Appl. Microbiol. Biotechnol. 43:880-886, 1995.

27. Rodrigues, M.F.A.; Vicente, E.J.; Steinbüchel, A. Studies on polyhydroxyalkanoate (PHA) accumulation in a PHA synthase Inegative mutant of Burkholderia cepacia generated by homogenization. FEMS Microbiol. Lett. 193:179-185, 2000.

28. Sánchez, R.J.; Schripsema, J.; Silva, L.F.; Taciro, M.K.; Pradella, J.G.C.; Gomez, J.G.C. Medium-chain-length polyhydroxyalkanoic acids (PHAmcl) produced by Pseudomonas putida IPT 046 from renewable sources. Eur. Polym. J. 39:1385-1394, 2003.

29. Shirling, E.B.; Gottlieb, D. Methods for characterization of Streptomyces species. Int. J. Syst. Bact. 16:313-340, 1966.

30. Spiekermann, P.; Rehm, B.H.; Kalscheuer, R.; Baumeister, D.; Steinbüchel, A. A sensitive, viable-colony staining method using Nile red for direct screening of bacteria that accumulate polyhydroxyalkanoic acids and other lipid storage compounds. Arch. Microbiol. 171:73-80, 1999.

31. Sudesh, K.; Abe, H.; Doi, Y. Synthesis, structure and properties of polyhydroxyalkanoates: biological polyesters. Prog. Polym. Sci. 25:1503-1555, 2000.

32. Tamura, K. Estimation of the number of nucleotide substitutions when there are strong transitition-transversion and $\mathrm{G}+\mathrm{C}$-content biases. Mol. Biol. Evol. 9:678-687, 1992

33. Tamura, K.; Dudley, J.; Nei, M.; Kumar, S. MEGA4: Molecular evolutionary genetics analysis (MEGA) software version 4.0. Mol. Biol.
Evol. 24:1596-1599, 2007.

34. Valappil, S.P.; Boccaccini, A.R.; Bucke, C.; Roy, I. Polyhydroxyalkanoates in Gram-positive bacteria: insights from the genera Bacillus and Streptomyces. Antonie Leeuwenhoek. 91:1-17, 2007.

35. Valappil, S.P.; Boccaccini, A.R.; Bucke, C.; Roy, I. Polyhydroxyalkanoates in Gram-positive bacteria: insights from the genera Bacillus and Streptomyces. Antonie Leeuwenhoek. 91:1-17, 2007.

36. Valentin, H.E.; Berger, P.A.; Gruys, K.J.; Rodrigues, M.F.A.; Steinbüchel, A.; Tran, M.; Asrar, J. Biosynthesis and Characterization of Poly(3-hydroxy-4-pentenoic acid). Macromol. 32:7389-7395, 1999.

37. Vandamme, P.; Coenye, T. (2004) Taxonomy of the genus Cupriavidus: a tale of lost and found. Int. J. Syst. Evol. Microbiol. 54 (6), 2285-2289.

38. Vandamme, P.; Holmes, B.; Vancanneyt, M.; Coenye, T.; Hoste, B.; Coopman, R.; Revets, H.; Lauwers, S.; Gillis, M.; Kersters, K.; Govan, J.R. Occurrence of multiple genomovars of Burkholderia cepacia in cystic fibrosis patients and proposal of Burkholderia multivorans sp. nov. Int. J. Syst. Bacteriol. 47:1188-1200, 1997.

39. Wang, Q.; Garrity, G.M.; Tiedje, J.M.; Cole, J.R. Naive Bayesian classifier for rapid assignment of rRNA sequences into the new bacterial taxonomy. Appl. Environ. Microbiol. 73:5261-5267, 2007.

40. Witholt, B.; Kessler, B. Perspectives of medium chain length poly(hydroxyalkanoates), a versatile set of bacterial bioplastics. Curr. Opin. Biotechnol. 10:279-285, 1999. 